\title{
O DIREITO À VIDA
}

\section{Luciana Mendes Pereira Roberto*}

SUMÁRIO: 1. Introdução: A Vida - O Direito à Vida. 2. O Direito à Vida ea Dignidade na Constituiçáo Federal. 3. Início da Personalidade Natural. 4. A Vida como Direito da Personalidade. 4.1. Sancöes. 5. Fim da Personalidade Natural (Morte). 6. Conclusâo. 7.Bibliografia.

SUMMARY: 1. Introduction: The life-The Right to the Life. 2. The Right to the Life and to the Dignity in the Federal Constitution. 3. Start of the Natural Personality. 4. The Life as Personality Right. 4.1. Sanction 5. End of Natural Personality (Death) 6. Conclusion. 7. Bibliography.

SUMARIO: 1. Introducción: La Vida - El Derecho a la Vida. 2. El Derecho a la Vida y a la Dignidad en la Constituición Federal. 3. Início de la Personalidad Natural. 4. La Vida como Derecho de la Personalidad. 4.1. Sanciones. 5. Fin de la Personalidad Natural (Muerte). 6. Conchsión. 7. Bibliografia.

RESUMO: A Vida é o bem fundamental do ser humano, pois sem a vida, não há que se falat em outros direitos, nen mesmo os de personalidade. Com base nesse entendimento, todo o homem tem direito à vida, ou seja, o direito de viver e não apenas isso, tem o direito de uma vida plena e digna, respeito aos seus valores e necessidades. Procurase, neste estudo, mostrar o início da vida para o Direito, ben como o seu fim, con a morte. Busca-se tambén clucidar a vida como direito primordial da personalidade, e as sancöes de tal transgressão.

ABSTRACT: The Life is the basic property of the human being, because without the life, there is no way to talk about other rights, not even about the personality ones. According to this understading, each single man has the right to the life, ie, the right to live, and not even it, he also has the right to a full and a dignified hife, respect to their values and requeriments. In this study, the start of the life to the Right is showed, as well its ending, with the death. Also, it is tried to elucidate the life as a primordial right of the personality, and the sanctions of even transgression.

Mestranda en Direito Negocial. Professora na Unyersidade Estadual de Londrina UEL e no Centro Universitário Filadelfa - UNIFIL 
RESUMEN: La Vida es el bien fundamental del ser bumano, pues sin la vida, no hay como hablar sobre otros derechos, tampoco sobre los de personalidad. Con base en este entendimiento, todo hombre tiene derecho a la vida, o sea, el derecho de vivir y no tan solo eso, tiene el derecho de una vida plena y digna, respecto a sus valores y necesidades. Procurase, en este estudio, mostrar el inicio de la vida para el Derecho, y también el sú fin, con la muerte. Buscase también tornar claro la vida como derecho primordial de la personalidad, ya las sanciones de tal trangresión.

PALAVRAS-CHAVE: Vida. Petsonalidade. Dignidade. Direitos.

KEY-WORDS: Life. Personality. Dignity, Rights.

PALABRAS-LLAVES: Vida. Petsonalidad. Dignidad, Derechos.

\section{Introdução: $A$ Vida - O Direito à Vida}

Considerando a amplitude e importância da palavra, termo ou expressão VIDA, primeiramente alçamo-nos à Bíblia Sagrada², para lembrar que Deus criou a luz (dia), o firmamento (céu), a terra, o mar, o Sol, a Lua e as estrelas. Vendo que tudo isso, mesmo sendo maravilhoso, não era suficiente, criou então a VIDA, primeiro a vida vegetal (ervas, sementes, árvores, frutos) e depois criou a vida animal (pássaros, baleias, peixes, animais domésticos, répteis e feras). Coroando Seu trabalho, criou então o homem e mulher, tendo soprado sobre eles um sopro de vida, tornado-os seres viventes. (Gênesis, 1-2)

A palavra VIDA, é conceituada no Dicionário Houaiss da Língua Portuguesa ${ }^{3}$, sob diferentes aspectos, nos quais os que mais nos interessam, no que pertine ao Direito à Vida, são os seguintes:

...3 - o período de um ser vivo compreendido entre o nascimento e a morte; existência...5 - motivação que anima a existência de um ser vivo, que the dá entusiasmo ou prazer; alma, espírito...8 - o conjunto dos acontecimentos mais relevantes na existência de alguém; 9 - meio de subsistência ou sustento necessário para manter a vida... p. 2858.

\footnotetext{
CHAVES, Antonio. Direito à Vida e ao Próprio Corpo (intersexualidade, transexualidade, transplantes). $2^{2}$ ed. revista e ampliada. São Paulo: Editora Revista dos Tribunais, 1994., p. 25 . O autor conclui esta frase, aduzindo que o abortamento, salvo en casos excepcionais, trata-se de crime.

- Bíblia Sagrada, Ediçäo Pastoral. Săo Paulo: Sociedade Biblica Católica Internacional e Paulus, 1990. Dicionário Houaiss da Lingua Portuguesa. Rio de Janeiro: Objetrva, 2001.
} 
Impossível falar em vida e na sua tutela, sem lembrar as palavras de ANTOONIO CHAVES

Quem poderá definir essa pulsação misteriosa, própria dos organismos animais e vegetais, que sopita inadvertida nas sementes de trigo encontradas nos sarcófagos de faraós egípcios e que germina milagrosamente depois de dois milênios de escuridão, que se oculta na gema de uma roseira que mãos habilidosas transplantam de uma para outro caule, que lateja, irrompe e transborda na inflorescência de milhões de espermatozóides que iniciam sua corrida frenética à procura de um único óvulo, a cada encontro amoroso?

$O$ autor acima citado, aduz ainda que o conceito de vida, proveniente da Psicologia, é algo que oscila entre um interior e um exterior, entre uma "alma" e um "corpo".

Cita o filósofo alemão Georg Simmel que imagina a vida como uma corrente contínua através das gerações sucessivas... uma continuidade sem limites e ao próprio tempo.

O Pacto Internacional sobre Direitos Civis e Politicos, aprovado pela XXI sessão da Assembléia Geral das Nações Unidas, reza que 1. O direito à vida é inerente à pessoa humana. Este direito deverá ser protegido pela lei, ninguém poderá ser arbitrariamente provado de sua vida. (Parte III, art. 6).

DE CUPIS afirma que a vida se identifica com a simples existência biológica e que o direito à vida é essencial, tem como objeto um bem muito elevado, sendo um direito essencialíssimo. É um direito inato, adquirido no nascimento, portanto, intransmissível, irrenunciável e indisponível. Assim, o suicídio não constitui ato de exercício de um direito

Assim, o direito à vida deve ser associado a um direito à conservação da vida, em que o indivíduo pode gerir e defender sua vida, mas não pode dela dispor, apenas justificando ação lesiva contra a vida em casos de legítima defesa e estado de necessidade. Assevera, ainda, sobre tutela privada e pública do direito à vida, admitindo que o direito aos alimentos é uma tutela complementar da vida, sendo diferente do direito à vida, pois não é a vida o seu objeto, mas um bem material para servir a conservação da vida.

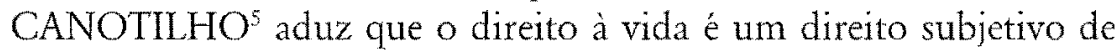
defesa, pois é indiscutível o direito de o individuo afirmar o direito de viver, com a garantia da "não agressão" ao direito à vida, implicando

\footnotetext{
CHAVES, Antônio. Direito à vida e à própro corpo (intersexualidade, transexualidade, transplantes). $2^{\circ}$ ed. revista c ampliada. São Paulo: Editora Reyista dos Tribunais, 1994., p. 16.

"CANOTILHO, José Joaquim Gomes. Direito Constitucional e Teoria da Constituição. $4^{\circ}$ edição. Coimbra [Portugat]: Livraria Almedina, 2000. p. 526/533/539. 
também a garantia de uma dimensão protetiva deste direito à vida, $\mathrm{Ou}$ seja, o indivíduo tem o direito perante o Estado a não ser morto por este, o Estado tem a obrigação de se abster de atentar contra a vida do indivíduo, e por outro lado, o indivíduo tem o direito à vida perante os outros indivíduos e estes devem abster-se de praticar atos que atentem contra a vida de alguém. E conclui: o direito à vida é um direito, mas não é uma liberdade.

CAPELO DE SOUZA', ao seu tempo revela: A vida humana, qualquer que seja sua origem, apresenta-se-nos, antes de mais, como um fluxo de projeção colectivo, contínuo, transmissivel, comum a toda a espécie humana e presente em cada indivíduo humano, enquanto depositário, continuador e transmitente dessa energia vital global...constitui um elemento promordial e estruturante da personalidade...a vida humana é susceptível de diversas perpectivaçöes...

O autor supra, entende que não há apenas um direito de vida (a conservação da vida existente), mas também um direito à vida (ao desdobramento e evolução da vida e até mesmo à consecução do nascimento com vida) ${ }^{7}$.

ALFREDO ORGAZ ${ }^{8}$, aduz que a vida constitui um pressuposto essencial da qualidade de pessoa e não um direito subjetivo desta, sendo tutelada publicamente, independente da vontade dos indivíduos. O consentimento dos indivíduos é absolutamente ineficaz para mudar esta tutela, não sendo possível, assim, haver um verdadeiro "direito" privado à vida. Neste sentido, são absolutamente nulos todos os atos jurídicos nos quais uma pessoa coloca sua vida à disposição de outra ou se submeta a grave perigo.

Exceções há nos casos de submissão à experimentação científica perigosa quando se trata da preservação urgente da saúde da coletividade, de forma gratuita, por exemplo. Mas estas exceçôes devem ser submetidas à valoração nos limites da ordem pública e dos bons costumes.

Assim como DE CUPIS, que entende que ninguém tem o direito de tirar a vida de outrem, nem mesmo o próprio titular, CAPELO DE SOU$Z A$, afirma que a vida humana constitui um bem jurídico, objeto de relações jurídicas ${ }^{9}$, porém é intransferivel e indisponível ${ }^{10}$, apontando

\footnotetext{
-SOUZA, Reindranath V. A. Capelo de. O Direito Geral de Personalidade. Coimbra, Portugal: Combra Editora, 1995. p. 203/204.

${ }^{7}$ Obra citada, p. 207.

:ORGAZ, Alfredo. Personas Individuales. Buenos Aires, Argentina: Editorial Depalma, 1947.

"Obra citada, p. 211.

1) Obra citada, p. $403 / 404$.
} 
para as mesmas exceções apresentadas por DE CUPIS, tais sejam, a legítima defesa e o estado de necessidade. Aduz também que é inválido o consentimento de alguém no sentido da privação de sua vida ${ }^{11}$.

\section{O Direito à Vida e à Dignidade na Constituição Federal}

O Art. $5^{2}$, caput da Constituição Federal de $1988^{12}$, assegura a todos aos brasileiros e estrangeiros residentes no Brasil, o direito à vida:

Art. $5^{a}$. Todos são iguais perante a lei, sem distinção de qualquer natureza, garantindo-se aos brasileiros e aos estrangeiros residentes no País a inviolabilidade do direito à vida, à liberdade, à igualdade, à segurança e à propriedade.

Como acentua ALEXANDRE DE MORAES ${ }^{13}$, o direito à vida é o mais fundamental de todos os direitos, já que constitui-se em pré-requisito a existência e exercício de todos os demais direitos. A Constituição Federal, é importante ressaltar, protege a vida de forma geral, inclusive a uterina.

CRETELLA JUNIOR, ${ }^{14} \mathrm{em}$ seus Comentários à Constituição Brasileira de 1988, estatui que: Bastaria que se tivesse dito "o direito" ao invés de "a inviolabilidade do direito à vida". Se "vida é um direito" garantido pelo Estado, esse direito é inviolável, embora não "inviolado". Se eu digo que é 'inviolável' (a correspondência, a intimidade, a residência, o sigilo profissional), 'ipso facto', estou querendo dizer que se trata de rol de bens jurídicos dotados de inviolabilidade (inviolabilidade da correspondência, da intimidade, da residência, do sigilo profissional)... O direito à vida é o primeiro dos direitos invioláveis, assegurados pela Constituição. Direito à vida é expressão que tem, no mínimo, dois sentidos, (a) o "direito a continuar vivo, embora se esteja com saúde" e (b) "o direito de subsistência": o primeiro, ligado à segurança física da pessoa humana, quanto a agentes humanos ou não, que possam ameaçar-lhe a existência; o segundo, ligado ao "direito de prover à própria existência, mediante trabalho honesto"...

\footnotetext{
"Obra citada, p. 205/206.

: CONSTTUICÄO DA REPÚ́BIICA FEDERATIVA DO BRASIL - Promulgada em 05 de outubro de 1988.

${ }^{13}$ MORAES, Alexandre ce Direito Constitucional. $8^{\circ}$ ed. São Paulo: Editora Atlas S. A., 2000, p. 61.

14 CRETELLA JUNIOR, José Comentários à Constituição Brasileira de 1988. vol. I, art. $1^{\text {a }}$ a $5^{\mathrm{a}}$, LXVI. Rio de Janeiro: Editora Forense Universitária, 1988. p. 182/183.
} 
No mesmo sentido as considerações de MARIA HELENA DINIZ ${ }^{15}$ : O direito à vida, por ser essencial ao ser humano, condiciona os demais direitos da personalidade. A Constituição Federal de 1988, em seu art. 5ª, caput, assegura a inviolabilidade do direito à vida, ou seja, a integralidade existencial, conseqüentemente, a vida é um bem jurídico tutelado como direito fundamental básico desde a concepção, momento específico, comprovado cientificamente, da formação da pessoa. Se assim é, a vida humana deve ser protegida contra tudo e contra todos, pois é objeto de direito personalíssimo. O respeito a ela e aos demais bens ou direitos correlatos decorre de um dever absoluto 'erga omnes', por sua própria natureza, ao qual a ninguém é lícito desobedecer...Garantido está o direito à vida pela norma constitucional em cláusula pétrea, que é intangível, pois contra ela nem mesmo há o poder de emendar...tem eficácia positiva e negativa...A vida é um bem jurídico de tal grandeza que se deve protegê-lo contra a insânia coletiva, que preconiza a legalização do aborto, a pena de morte e a guerra, criando-se normas impeditivas da prática de crueldades inúteis e degradantes...Estamos no limiar de um grande desafio do século XXI, qual seja, manter o respeito à dignidade humana.

Neste sentido, PONTES DE MIRANDA ${ }^{16}$ assevera: $O$ direito à vida é inato; quem nasce com vida, tem direito a ela...Em relação às leis e outros atos, normativos, dos poderes públicos, a incolumidade da vida é assegurada pelas regras jurídicas constitucionais e garantida pela decretação da inconstitucionalidade daquelas leis ou atos normativos...O direito à vida é direito ubíquo: existe em qualquer ramo do direito, inclusive no sistema jurídico supraestatal...O direito à vida é inconfundível com o direito à comida, às vestes, a remédios, à casa, que se tem de organizar na ordem política e depende do grau de evolução do sistema jurídico constitucional ou administrativo...O direito à vida passa à frente do direito à integridade física ou psíquica...o direito de personalidade à integridade física cede ao direito de personalidade à vida è̀ integridade psíquica...

ALEXANDRE DE MORAES, lembra-nos que: A Constituição Federal proclama, portanto, o direito à vida, cabendo ao Estado assegurá-lo em sua dupla acepção, sendo a primeira relacionada ao direito de continuar vivo e a segunda de se ter vida digna quanto à subsistência ${ }^{17}$.

15 DINIZ, Maria Helena. O Estado Atual do Biodireito. São Paulo: Editora Saraiva, 2001. p. 22/24.

to PONTES DE MIRANDA. Tratado de Direito Privado. Parte Especial, Tomo VII. $3^{\circ}$ ed, reimpressão. Rio de Janeiro, Editor Borsoi: 1971. p. 14/29.

${ }^{17}$ Obra citada, p. 62. 
Já PONTES DE MIRANDA, faz uma comparação bastante interessante, no que concerne à dignidade da vida humana, senão vejamos: $O$ direito ao salário mínimo, que não se confunde com o direito ao mínimo vital, que é o direito à existência ${ }^{18} \ldots$

O Dicionário Houaiss da Língua Portuguesa ${ }^{19}$, assim define dignidade: 1. qualidade moral que infunde respeito; consciência do próprio valor; honra... 4. respeito aos próprios sentimentos, valores; amor-próprio...

Portanto, a vida constitucionalmente referida não é uma vida qualquer. Seu conceito se apóia noutra definição constitucional que é a da dignidade, vale dizer, o legislador constitucional propugna pela defesa da vida digna.

ELIMAR SZANIAWISK ${ }^{20}$, citando Gonella, afirma que a idéia de dignidade teve origem na concepção cristã de pessoa como uma substância racional, e no princípio da imortalidade da alma e na ressurreição do corpo.

CAPELO DE SOUZA ${ }^{21}$, citando Antônio Luiz de Seabra, tecendo comentários sobre a Constituição Portuguesa, diz que o termo "dignidade" é mais abrangente que "vida", ou seja, não basta a vida, se esta não é digna. ...todos os seres humanos têm a mesma dignidade vital...22

Pondera CANOTILHO ${ }^{23}$ : Outra esfera constitutiva da República Portuguesa é a dignidade da pessoa humana (artigo 2o.). O que é ou que sentido uma República baseada na dignidade da pessoa humana?A resposta deve tomar em consideração o princípio material subjacente à idéia de dignidade da pessoa humana. Trata-se do 'princípio antrópico' que acolhe a idéia pré-moderna e moderna da 'dignitas-hominis' (Pico della Mirandola) ou seja, do indivíduo formador de si próprio e de sua vida segundo o seu projecto espiritual ('plastes et fictor').

Perante as experiências históricas de aniquilação do ser humano (inquisição, escravatura, nazismo, stalinismo, polpotismo, genocidios étnicos) a dignidade da pessoa humana como base da República significa, sem transcendências ou metafísicas o reconhecimento do 'homo noumenon', ou seja, do indivíduo como limite e fundamento do domínio político da

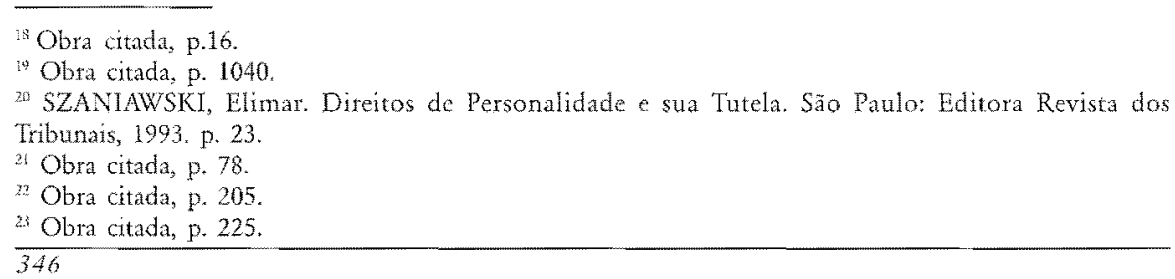


República. Nesse sentido, a República é uma organização política que serve o homem, não é o homem que serve os aparelhos político-organizatórios...

Por último, a dignidade da pessoa humana exprime a abertura da República à idéia de comunidade constitucional inclusiva pautada pelo multiculturalismo mundividencial, religioso ou filosófico...

O Estatuto da Criança e do Adolescente (Lei n⿳a 8069/90), em seu artigo 7aㅗ afirma que a criança e o adolescente têm a proteção à vida e à saúde, mediante a efetivação de políticas sociais públicas que permitam o nascimento e o desenvolvimento sadio e harmonioso, em condições dignas de existência. O artigo $8^{\mathrm{a}}$ complementa tal garantia: ...incumbe ao Poder Público propiciar apoio alimentar à gestante e à nutriz que dele necessitem. Assim, o direito à vida, possui uma íntima ligação com a dignidade, ou poderia dizer, ainda, a plenitude da vida. Isto significa que o direito à vida não é apenas o direito de sobreviver, mas de viver dignamente.

Nessa esteira, a Constituição Federal refere-se ao direito à vida, não somente no caput do Art. $5^{\text {a }}$, mas também em artigos esparsos, como por exemplo o Art. $227^{24}$ e o Art. $230^{25}$.

Muitos dos direitos fundamentais são direitos de personalidade ${ }^{26}$, mas

${ }^{24}$ Art. 227. É dever da família, da sociedade e do Estado assegurar à criança e ao adolescente, com absoluta prioridade, o cireito à vida,...

${ }^{55}$ Art. 230. A família, a sociedade e o Estado têm o dever de amparas as pessoas idosas...e garantindo-thes o direito à vida.

26. Direito da Personalidade: A idéia dos direitos da personalidade está vinculada ao reconhecimento de valores inerentes à pessoa humana, imprescindiveis ao desenvolvimento de suas potencialidades físicas, psíquicas e morais, tais como a vida, a incolumidade fisica e psíquica, o próprio corpo, o nome, a imagem, a honra, a privacidade, entre outros...pode-se afirmar que a dignidade humana é o objeto, ao final dos direitos da personalidade. (www2.correioweb.com.br/cw/2001-06-18/mat_42326.htm. Acesso em 14/10/ 2002. Autor: Leonardo Roscoe Bessa, Titular da Segunda Promotoria de Defesa do Consumidor do Ministério Público do Distrito Federal e Territórios, mestrando pela UNB e professor de Direito Civil). ...existem certos direitos sem os quais a personalidade restaria uma susceptibilidade completamente irrealizada, privada de todo o valor concreto: direitos sem os quais outros direitos subjetivos perderiam todo o interesse para o indivíduo... (Adriano de Cupis, Os Direitos da Personalidade, Editora Livraria Morais, p. 17)

Os Direitos da Personalidade foram introduzidos no Novo Código Civil, no Livro I, Título I, Capítulo II, nos artigos 11 a 21. Dispõe o artigo 11: Com exceção dos casos previstos em lei, os direitos da personalidade são intransmissíveis e irrenunciáveis, não podendo o seu exercício sofrer limitação voluntária. Especificamentc à disposição do próprio corpo, os artigos 13,14 e 15. Dispöe o artigo 13: Salvo por exigência médica, é defeso o ato de disposição do próprio corpo, quando importar diminuição permanente da integridade fisica, ou contrariar os bons costumes. Parágrafo Único. $\mathrm{O}$ ato previsto neste artigo será admitido para fins de transplante, na forma estabelecida em lei especial. Artigo 14: É válida, com objetivo científico, ou altruístico, a disposição gratuita do próprio corpo, no todo em parte, para depois da morte. Parágrafo Único. $O$ ato de disposição pode ser livremente revogado a qualquer tempo. Artigo 15: Ninguem pode ser constrangido a submeter-se, com risco de vida, a tratamento médico ou a intervenção cirúrgica. (Novo Código Civil Comentado, coordenação Ricardo Fiuza, Editora Saraiva, p.22/28)

Godoffredo Telles $\mathbf{J}$ r, ensina que ...os direitos da personalidade são os direitos subjetivos da pessoa de defender o que the é próprio, ou seja, a vida, a integridade, a liberdade, a sociabilidade, a reputação ou honra, a imagem, a privacidade, a autoria etc.(Enciclopédia Saraiva do Direito, Direito Subjetivo I, vol 28, p. 315-6) 
nem todos os direitos fundamentais são direitos de personalidade. Os direitos de personalidade abarcam certamente os direitos de estado (por ex.: direito de cidadania), os direitos sobre a própria pessoa (direito à vida, à integridade moral e física, direito à privacidade, direito à imagem), os direitos distintivos da personalidade (direito à identidade pessoal, direito à informática) e muitos dos direitos de liberdade (liberdade de expressão)...27

\section{Início da Personalidade Natural}

O ordenamento brasileiro, através do Código Civil, reza que a responsabilidade civil da pessoa começa do nascimento com vida, pondo a salvo, desde a concepção, os direitos do nascituro.

Quanto ao nascimento com vida, a partir dá, a pessoa adquire a plenitude da sua personalidade jurídica, podendo ser sujeito ativo e passivo do direito ${ }^{28}$. Daí, ou seja, do nascimento com vida, se distinguem dois elementos: o nascimento e com vida.

LIMONGI FRANCA, explica que nascimento é a 'separação do filho das vísceras maternais'... Assim, a criança se encontra nascida. E completa: O elemento 'vida', que deve acompanhar o nascimento, parece caracterizar-se pela respiração pulmonar, pois é este o primeiro indício de que a criança já não se alimenta através do organismo materno. Basta um só instante de vida e a personalidade está caracterizada. ${ }^{29}$

O nascituro, por sua vez, é o ente já concebido no ventre materno, aquele que há ou deve nascer. Nesta condição, a personalidade já existe com a concepção, e será consolidada com o nascimento.

Os direitos do nascituro são tutelados pela lei civil, que póe os a salvo desde a concepção, e também pela lei penal, tendo em vista a punição do aborto, do infanticídio durante o parto, da periclitação da vida e da saúde, entre outros.

DE CUPIS ${ }^{30}$ ressalta que a concepção é o ato inicial da vida, tanto da vida física, como da vida jurídica.

ORGAZ $^{31}$ faz menção de que antes de nascer, o embrião humano já tem proteção pública e privada, exemplificando no direito argentino:

\footnotetext{
27 CANOTYLHO, Jose Joaquim Gomes. Obra citada, p. 390.

FRANCA, R. Limongi. Instutuiçóes de diretro Civil. $4^{\circ}$ ed, atualizada, São Paulo: Editora Sarava, 1996. p.47.

2* Obra citada, $0.47 / 48$.

DE CUPS, Adrino. I Dintu della Personalitả. $2^{2}$ ed. Milà Itália: Dott A. Giufré Editore, p. 101 a 110.

"ORGAZ, Afredo. Personas Individuales.Buenos Ares, Argentina: Editorial Depalma, 1947. p. 135 a 138. 
- aborto: norma penal

- alimentos à mulher grávida: norma civil

- licença-gestante: norma trabalhista

Lembra também da proteção do ser humano nascido, na citada legislação:

- homicídio, instigação e ajuda ao suicídio: norma penal

- alimentos, reparação civil por lesões à vida: norma civil

- direito à amamentação: norma trabalhista

É a fecundação que marca o início da vida. Estas são palavras de ANTÔNIO CHAVES ${ }^{32}$, que é do entendimento que no momento da fecundação, mesmo fora do corpo da mulher, os cromossomos femininos e masculinos definem o novo ser humano e qualquer método artificial para destruí-lo põe fím à vida.

Em sua obra Direito à Vida e ao Próprio Corpo, ANTÔNIO CHAVES, traz uma série de entendimentos no que pertine ao início da vida. Como exemplo as palavras do geneticista francês: ...A natureza do ser humano desde a concepção até a velhice, não é uma hipótese metafísica, mas, sim, uma evidência experimental.

A vida, nos dizeres de CAPELO DE SOUZA ${ }^{33}$...deve ser tomada na totalidade da sua fenomenologia biológica, ao longo do seu processo mutacional, desde o seu início individualizado com a concepção até a sua morte.

\section{A Vida como Direito da Personalidade}

CAPELO DE SOUZA, cita o alemão Hugo Donnelus que distinguia no objeto do direito sobre a própria pessoa quatro bens: a vida, a incolumidade corporal, a liberdade e a reputação $0^{34}$. Já Hubmann, divide o conjunto complexo dos valores da personalidade em 3 grandes gru$\operatorname{pos}^{35}$ :

- desenvolvimento da personalidade (liberdade);

- existência (vida, conservação da vida, saúde, corpo), espírito, vontade e vida sentimental;

- individualidade (honra, imagem)

\footnotetext{
32 Obra citada, p. 13.

3. Obra citada, p. 204.

34 Obra citada, p. 124.

35 Obra citada, p. $147 / 148$.
} 
CAPELO DE SOUZA, fala ainda em direitos especiais de personalidade: vida, integridade fisica, liberdade, honra, bom nome, saúde e repouso; e bens interiores da personalidade: a vida, a integridade física e a identidade ${ }^{36}$.

SZANIAWSKI ${ }^{37}$, afirma que os bens inerentes à pessoa humana, denominados de direitos da personalidade são: a vida, a liberdade e a honra, entre outros.

A classificação dos campos dentro dos quais podem incidir as relações juridicas, de acordo com LIMONGI FRANÇA, são:

- a própria pessoa (direitos de personalidade)

- a pessoa ampliada na família (direitos de família)

- o mundo exterior (direitos patrimoniais)

O ramo que nos interessa, com relação ao estudo do Direito à Vida, é o específico das relações jurídicas que envolvem a própria pessoa, conhecido por direitos da personalidade, que são as faculdades jurídicas cujo objeto são os diversos aspectos da própria pessoa do sujeito, bem assim da sua projeção essencial no mundo exterior. ${ }^{38}$

Nas relações jurídicas que envolvem a própria pessoa, há três aspectos essenciais a serem elencados: o físico, o intelectual e o moral. Dessa forma, sub-classifica-se: o direito à integridade física (direito à vida e aos alimentos; direito sobre o próprio corpo, vivo; direito sobre o próprio corpo, morto; direito sobre o corpo alheio, vivo; direito sobre o corpo alheio, morto; direito sobre partes separadas do corpo, vivo; direito sobre partes separadas do corpo, morto); direito à integridade intelectual (direito à liberdade de pensamento; direito pessoal de autor científico; direito pessoal de autor artístico; direito pessoal de inventor); direito à integridade moral (direito à liberdade civil, política e religiosa; direito à honra; direito à honorificência; direito ao recato; direito ao segredo pessoal, doméstico e profissional; direito à imagem; direito à identidade pessoal, familiar e social).

$O$ direito à vida e o direito ao próprio corpo vivo, estão intimamente ligados, tendo em vista que irão abranger uma série de matérias que consideram: a vida; a condição jurídica do nascituro; o direito à velhice; a eutanásia; o direito ao gene e ao óvulo; a gravidez extra-uterina; a inseminação artificial; o transexualismo, homossexualismo e intersexualismo; o planejamento familiar (esterilização); o aborto; a cirurgia plástica estética e corretiva; transplante de órgãos; a prorrogação artificial da vida; a reanimação; outros.

\footnotetext{
Obra citada, p. 184.

3 Obea citada, p. 35 .

* LMONGI FRANCA, obra citada, p.1033. 


\subsection{Sansões}

Tal a grandiosidade e a importância dos direitos da personalidade, em específico do direito à vida, que merecem uma dupla sanção: a pública e a privada.

A sanção pública apresenta a feição constitucional (garantia ao direito à vida e à dignidade) e a penal (homicídio; induzimento, instigação ou auxílio ao suicídio; infanticídio; aborto).

Por sua vez, a sanção privada é caracterizada especialmente pelas indenizações pelos danos materiais e morais (civis), causados contra a vida de outrem, mas também pelas sanções na esfera administrativa, por exemplo, no âmbito dos órgãos de classe (Conselho Federal ou Regional de Medicina, entre outros).

CAPELO DE SOUZA, lembra que os bens jurídicos de personalidade: a vida, o corpo, a saúde e a liberdade, devem ser indenizados em caso de lesão ${ }^{39}$ (proteção civil) e que a vida é protegida pelo Direito Penal ${ }^{40}$, e que para a tutela eficaz da personalidade humana importará ter em conta o conjunto, as fases e as intensidades de todo o processo histórico de cada homem...tenha em conta não apenas a situação do lesado aquando da ofensa, mas também a sua 'esperança de vida'"41.

Aduz, ainda, citado autor que para a Constituição Portuguesa a vida é inviolável ${ }^{42}$ e esta se encontra protegida desde a sua concepção, pois o Código Penal português prevê os crimes contra a vida intra-uterina ${ }^{43}$ e o Código Civil tutela a personalidade física e moral do nascituro ${ }^{44}$.

\section{Fim da Personalidade Natural (Morte)}

O Código Civil determina que a existência da pessoa natural termina com a morte. LIMONGI FRANÇA, explica que mais de uma espécie de morte, a natural e a presumida.

A morte natural é "o limite do ciclo vital do homem" ${ }^{45}$, isto implica que a partir da morte natural a pessoa humana perde sua vida biológica, extinguindo sua personalidade natural. A morte presumida ocorre no caso dos

\footnotetext{
3y) Obra citada, p. 82.

*) Obra citada, p. 101

4l Obra citada, p. 156

42 Obra citada, p. 157

${ }^{43}$ Obra citada, p. 158

4 Obra citada, p. 159

45 LIMONGI FRANCA, obra citada, p. 62.
} 
ausentes, especificados no Código Civil brasileiro, com a declaração pelo juiz, quando passados dois anos sem que se saiba do ausente, ou vinte anos depois de passada em julgado a sentença de abertura da sucessão provisória do ausente, ou ainda o ausente com oitenta anos de nascido e de cinco datam as suas últimas notícias.

ANTONNIO CHAVES ${ }^{46}$ explica que a morte é a cessação de toda a atividade funcional peculiar a animais e vegetais, tempo decorrido entre o começo e o fim da existência.

\section{Conclusão}

Em sede de conclusão, observou-se no transcorrer desse estudo, a importância máxima da vida para o ser humano. Diversas foram as colações de autores que, se discordam em pormenores, concordam todos sobre a primazia da vida sobre os direitos da personalidade.

Importante lembrar que tal primazia deve ser sempre acompanhada pela dignidade e pela liberdade, para não ocorrer o que GIOSTRI ${ }^{47} \mathrm{cha}^{-}$ ma de idolatria da vida. Tal seja quando a vida física é considerada o bem supremo e absoluto... o amor natural pela vida se transforma em idolatria (citando: ASSAD, 1992:219-28). São os casos em que se defende a eutanásia, em prol da dignidade da pessoa. Assunto bastante discutível e polêmico, tratável em outra ocasião.

O que se faz necessário lembrar é o fato de que importa para o homem o resguardo ao seu direito à vida: digna e plena, direito esse adquirido desde o seu nascimento (resguardado o direito do feto) com vida, até a sua morte, com o culminar da personalidade juridica.

Observou-se, de acordo com o entendimento dos doutrinadores e das leis apostas, que a todo homem é devido respeito, liberdade e dignidade ao direito à vida, pois este é fundamental à sua existência. $E$, que ninguém pode desfazer-se da vida de outrem, sob pena de sanção pública e privada.

\footnotetext{
Sh Obra citada, p. 50 .

4 GIOSTRI, Hildegard Taggesell. O Paciente Terminal: Reflexöes sobre o limite do poder de escolha entre a vida a morte. Artigo publicado na Revista Argumenta, da Faculdade de Direito do Norte Pioneiro, 2002, p. 96 a 129.
} 


\section{BIBLIOGRAFIA}

BESSA, Leonardo Roscoe. Direitos de Personalidade. Em www2.correioweb.com.br. Acesso em 14/10/2002.

BÍBLIA SAGRADA, Edição Pastoral. São Paulo: Sociedade Bíblica Católica Internacional e Paulus, 1990.

CANOTILHO, José Joaquim Gomes. Direito Constitucional e Teoria da Constituição. 4 edição. Coimbra [Portugal]: Livraria Almedina, 2000.

CHAVES, Antônio. Direito à Vida e ao Próprio Corpo (intersexualidade, transexualidade, transplantes). $2^{\circ}$ ed. revista e ampliada. São Paulo: Editora Revista dos Tribunais, 1994.

CONSTITUIÇÃO DA REPÚBLICA FEDERATIVA DO BRASIL - Promulgada em 05 de outubro de 1988. São Paulo: Saraiva, 2003.

CRETELLA JÚNIOR, José. Comentários à Constituição Brasileira de 1988. v. I, art. 1a a 5aㅡ, LXVII. Rio de Janeiro: Editora Forense Universitária, 1988. DICIONÁRIO HOUAISS DA LÍNGUA PORTUGUESA. Rio de Janeiro: Objetiva, 2001.

DINIZ, Maria Helena. O Estado Atual do Biodireito. São Paulo: Editora Saraiva, 2001.

FIÚZZA, Ricardo (coord.). Novo Código Civil Comentado. São Paulo: Editora Saraiva, 2002.

FRANÇA, R. Limongi. Instituições de direito Civil. $4^{\circ}$ ed, atualizada. São Paulo: Editora Saraiva, 1996.

GIOSTRI, Hildegard Taggesell. O Paciente Terminal: Reflexões sobre o limite do poder de escolha entre a vida e a morte. Artigo publicado na Revista Argumenta, da Faculdade de Direito do Norte Pioneiro, 2002.

MORAES, Alexandre de. Direito Constitucional. $8^{\circ}$ ed. São Paulo: Editora Atlas S. A., 2000.

ORGAZ, Alfredo. Personas Individuales. Buenos Aires, Argentina: Editorial Depalma, 1947.

PONTES DE MIRANDA. Tratado de Direito Privado. Parte Especial, Tomo VII. $3^{\circ}$ ed, reimpressão. Rio de Janeiro, Editor Borsoi: 1971.

SOUZA, Reindranath V. A. Capelo de. O Direito Geral de Personalidade. Coimbra, Portugal: Coimbra Editora, 1995.

SZANIAWSKI, Elimar. Direitos de Personalidade e sua Tutela. São Paulo: Editora Revista dos Tribunais, 1993.

TELLES JR, Godoffredo. Enciclopédia Saraiva do Direito, Direito Subjetivo I, vol 28. São Paulo: Saraiva, 1977. 